\title{
An Eco-Friendly System for Oximation of Organic Carbonyl Compounds Under Microwave Irradiation
}

\author{
HANA BATMANI and DAVOOD SETAMDIDEH* \\ Department of Chemistry, College of Sciences, Mahabad Branch, \\ Islamic Azad University, Mahabad, Iran. \\ ${ }^{*}$ Corresponding author E-mail: d.setamdideh@iau-mahabad.ac.ir \\ http://dx.doi.org/10.13005/ojc/300241
}

(Received: April 11, 2014; Accepted: May 15, 2014)

\begin{abstract}
The oximation of a variety of organic carbonyl compounds was efficiently carried out with $\mathrm{NH}_{2} \mathrm{OH} \cdot \mathrm{HCl}$ under microwave irradiation. The reactions were performed in water or water-ethanol as green solvents to give $Z$-aldoxime isomers from the corresponding aldehydes and $E$-ketoxime isomers from the corresponding ketones in a perfect selectively with excellent yields.
\end{abstract}

Key words: Oximes, Z-aldoximes, E-acetophenone oximes, $\mathrm{H}_{2} \mathrm{NOH} . \mathrm{HCl}$, microwave irradiation.

\section{INTRODUCTION}

Microwave irradiation as an unconventional energy source has been widely used to carry out many kinds of chemical reactions. Many reviews and papers have demonstrated its importance. It is now clear that the microwave dielectric heating effect uses the ability of liquids to transform electromagnetic energy into heat and so drive chemical reactions effectively and quickly ${ }^{1}$. This in situ mode of energy conversion has attracted much attentions of chemists and has resulted in the development of many techniques to perform microwave-assisted organic reactions using domestic microwave ovens. On the other hand, the use of large amounts of conventional volatile solvents required to conduct a chemical reaction creates economic and ecological concerns. Consequently replacement of volatile organic solvents from reaction medium has been a major emphasis of green chemistry ${ }^{2}$. So, the use of water as a green solvent can be the best medium of choice to perform chemical reactions. In the last decades, a large number of publications have demonstrated the value of performing chemical reactions in water or aqueous media ${ }^{3 a-b}$. We have reported a fast and efficient method for the reduction of varieties of carbonyl compounds such as aldehydes, ketones, conjugated aldehydes and ketones, á-diketones and acyloins to their corresponding alcohols under microwave irradiation in water as green solvent ${ }^{3 c}$. Recently, the oximation methods has been reviewed ${ }^{4}$. The lack of information for systematic the oximation of carbonyl compounds in water 
under microwave irradiation and our ongoing attentions to the development of modified methods in organic synthesis ${ }^{5-23}$ encouraged us to investigate this transformation with $\mathrm{NH}_{2} \mathrm{OH} \cdot \mathrm{HCl}$ under microwave irradiation in water as a green and good solvent for transferring electromagnetic energy into heat and so driving an oximation reaction effectively. Herein, we describe a fast and efficient method for the oximation of varieties of carbonyl compounds such as aldehydes, ketones to the corresponding oximes with $\mathrm{NH}_{2} \mathrm{OH} \cdot \mathrm{HCl} / \mathrm{H}_{2} \mathrm{O} / \mathrm{MWI}$ system.

\section{RESULTS AND DISCUSSIONS}

The oximation of unsymmetrical carbonyl compounds usually give a mixture of the two geometrical isomers $(Z$ and $E$ ) of their corresponding oximes which have different physical properties and biological activities ${ }^{24}$. Thus, there is considerable interest in finding more selective methods for oximes synthesis. We now report a simple and efficient method for the preparation of oximes from their corresponding carbonyl compounds with $\mathrm{NH}_{2} \mathrm{OH} \cdot \mathrm{HCl} / \mathrm{H}_{2} \mathrm{O} /$ Microwave irradiation system.

In order to determine an appropriate reaction conditions for the oximation of aldehydes and ketones a model study was carried out on the oximation of bezaldehyde and acetophene. The results showed that using $\mathrm{NH}_{2} \mathrm{OH} . \mathrm{HCl}(1 \mathrm{mmol})$ in $\mathrm{H}_{2} \mathrm{O}(5 \mathrm{ml})$ and $30 \%$ power amplitude of microwave oven $(300 \mathrm{~W})$ was the best for the oximation of benzaldehyde. The reaction was completed in 90 sec with excellent yield (95\%). The results show that the use of 1 molar equivalents of $\mathrm{NH}_{2} \mathrm{OH} . \mathrm{HCl}$ is sufficient and no other additives are required for this conversion. In order to evaluate the generality of the process a variety of aldehydes were ground with hydroxylamine hydrochloride under microwave irradiation in water. In this approach, the corresponding $Z$-aldoximes were obtained in quantitative yield. The general reaction has been shown in scheme 1 and the results have been reported in table1 (entries 1-7).

The reaction of different aromatic aldehydes gave $Z$-aldoximes in excellent yields and stereoselectivity. The purity of the products was determined by ${ }^{1} \mathrm{H}-\mathrm{NMR}$ which showed the exclusive formation of the corresponding Z-aldoximes. The $Z$-stereochemistry of the products was determined from the ${ }^{1} \mathrm{H}$-chemical shift ${ }^{4}$ of the $\mathrm{C}(\mathrm{H})=\mathrm{N}$ group which appeared around 8-8.5 ppm as a singlet whereas the ${ }^{1} \mathrm{H}$-chemical shift of the $\mathrm{C}(\mathrm{H})=\mathrm{N}$ group for $E$-aldoximes appears in 7.30 and $7.60 \mathrm{ppm}$. In all the ${ }^{1} \mathrm{H}$-NMR spectra $\left(\mathrm{CDCl}_{3}, 25^{\circ} \mathrm{C}\right)$ by comparison of ${ }^{1} \mathrm{H}$-NMR of these isomers, we have observed the $\mathrm{C}(\mathrm{H})=\mathrm{N}$ signal in $8.10-8.49 \mathrm{ppm}$. The ${ }^{1} \mathrm{H}$-chemical shift of the $\mathrm{C}(\mathrm{H})=\mathrm{N}$ groups appears for $(Z)$-benzaldehyde oxime in $\delta 8.18 \mathrm{ppm},(Z)-4$ bromobenzaldehyde oxime in $\delta 8.10 \mathrm{ppm},(Z)-N$, $\mathrm{N}$-dimethylbenzaldehyde oxime in $\delta 8.07 \mathrm{ppm},(Z)$ 4 -methylbenzaldehyde oxime in $\delta 8.15 \mathrm{ppm}$, (Z)-3-methylbenzaldehyde oxime in $\delta 8.15 \mathrm{ppm},(Z)$ -

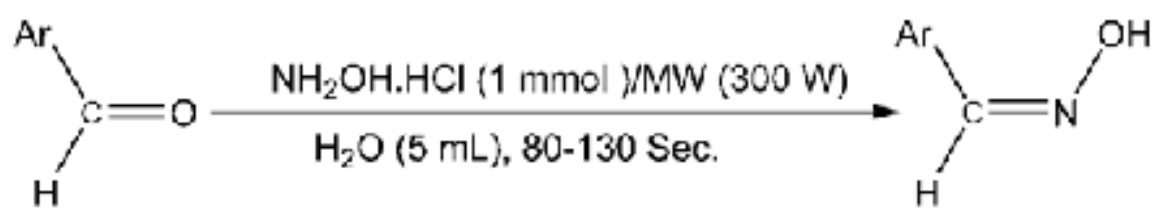

Scheme 1:

Z-aldoximes (92-98\%)

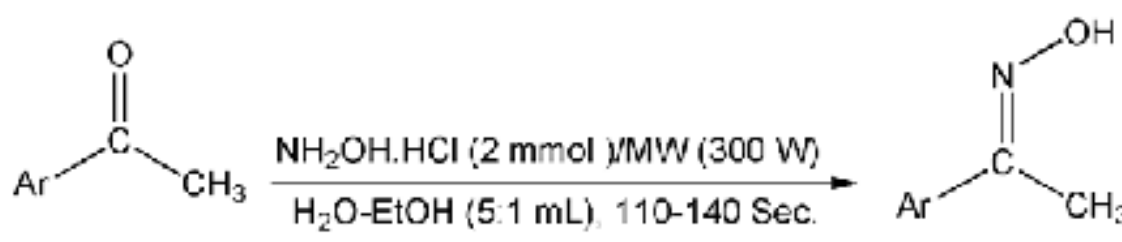

Ar: $\mathrm{Ph}, 4-\mathrm{MePh}, 4-\mathrm{MeOPh}$. $\mathrm{Ph}-\mathrm{CH}=\mathrm{CH}-$

$E$-isomer $(87-95 \%)$

Scheme 2: 


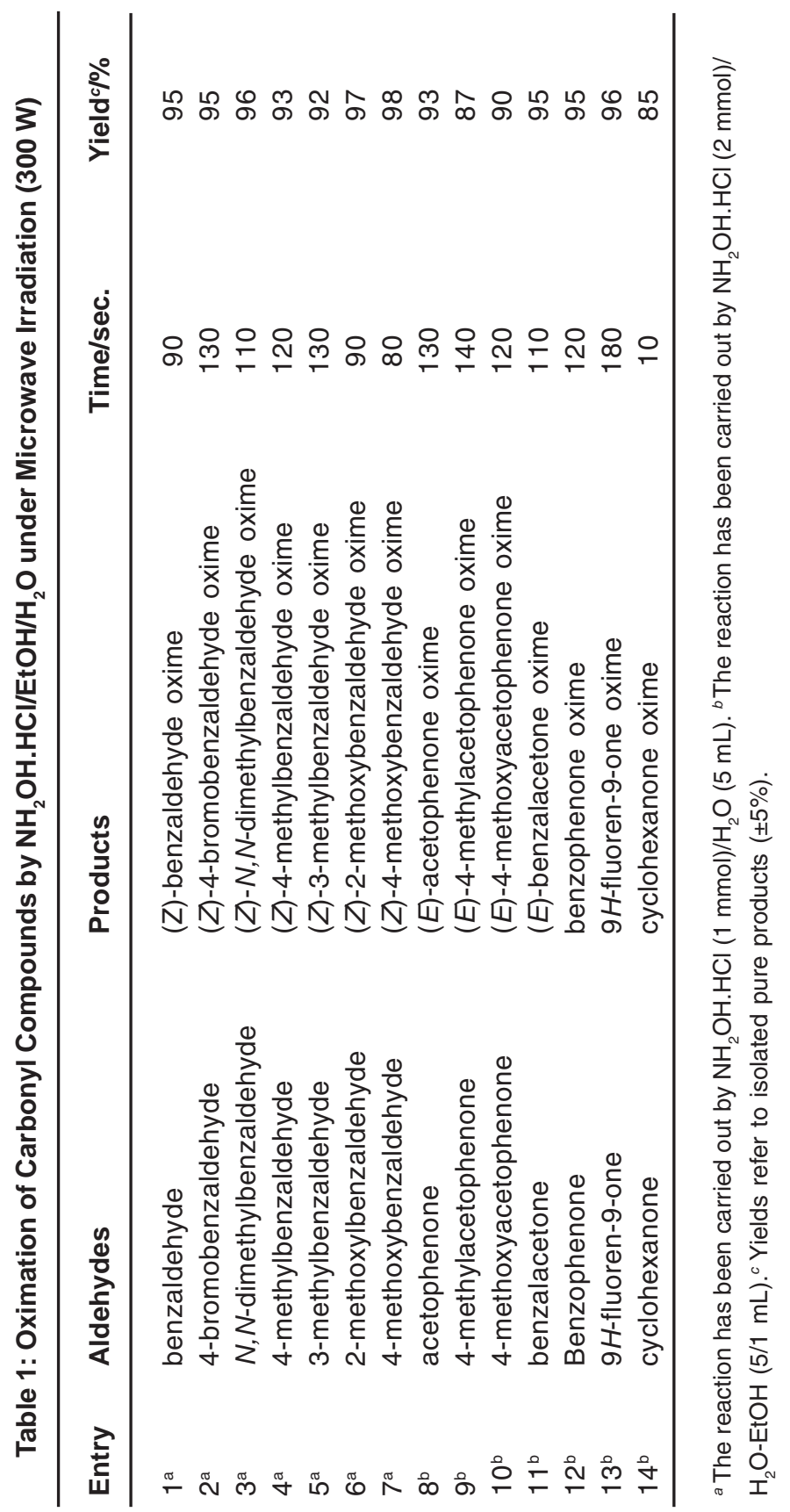


2-methoxybenzaldehyde oxime in $\delta 8.49 \mathrm{ppm}$ and (Z)-4-methoxybenzaldehyde oxime in $\delta 8.11 \mathrm{ppm}$.

The oximation of ketones was also performed well by $\mathrm{NH}_{2} \mathrm{OH} \cdot \mathrm{HCl} / \mathrm{H}_{2} \mathrm{O}-\mathrm{EtOH} /$ Microwave irradiation system but due to the lower reactivity of ketones relative to aldehydes, the oximation requires higher molar amounts of $\mathrm{NH} 2 \mathrm{OH} \cdot \mathrm{HCl}(2 \mathrm{mmol})$ vs. $1 \mathrm{mmol}$ of the substrates. E-acetophenone oximes (table 1, entries 8-11) were also obtained in high to excellent yields as shown in scheme 2.

The E-stereochemistry of acetophenone oxime derivatives was determined from the ${ }^{1} \mathrm{H}$ chemical shift of the $\mathrm{CH}_{3}$ group which appeared around $2.3 \mathrm{ppm}$ as a singlet whereas the ${ }^{1} \mathrm{H}$-chemical shift of the $\mathrm{CH}_{3}$ group for $Z$-ketoximes appeared around $2.6 \mathrm{ppm}$. In all the ${ }^{1} \mathrm{H}-\mathrm{NMR}$ spectra $\left(\mathrm{CDCl}_{3}, 25^{\circ} \mathrm{C}\right)$ by comparison of ${ }^{1} \mathrm{H}$-NMR of these isomers ${ }^{4}$, we have observed the $\mathrm{CH}_{3}$ signal in 2.30-2.34 ppm. The ${ }^{1} \mathrm{H}$ chemical shift of the $\mathrm{CH}_{3}$ groups appears for $(E)$ benzalacetone oxime in $\delta 2.34 \mathrm{ppm},(E)-4$ methylacetophenone oxime in $\delta 2.38 \mathrm{ppm}$, (E)-4-methoxyacetophenone oxime in $\delta 2.30 \mathrm{ppm}$ and $(E)$-benzalacetone oxime (as $\alpha, \beta$-unsaturated) in $\delta 2.18$. The Symmetric ketones (table 1, entries $12-$ 14). i.e. Benzophenone, 9H-fluoren-9-one and cyclohexanone were ground with hydroxylamine hydrochloride under microwave irradiation in water to their corresponding ketoximes in quantitative yields.

In order to show chemoselectivity of the presented oximation system a mixture of one equivalents of benzaldehyde and one equivalents of acetophenone was treated with $\mathrm{NH}_{2} \mathrm{OH} . \mathrm{HCl}$ $(1 \mathrm{mmol})$ under microwave irradiation in water. The oximation of aldehyde with respect to ketone was not satisfactory. In the most cases the selectivity ratios were not excellent. Therefore this methodology could not be used selectively for the preparation of aldoximes of compounds that contain both aldehyde and ketone functional groups.

\section{EXPERIMENTAL}

All microwave assisted reactions were carried out in a Yusch household microwave oven $(1000 \mathrm{~W})$. The instrument was modified for laboratory applications with an external reflux condenser. All substrates and reagents were purchased from commercially sources with the best quality. IR and ${ }^{1} \mathrm{H}$ NMR spectra were recorded on Perkin-Elmer FT-IR RXI and $300 \mathrm{MHz}$ Bruker spectrometers, respectively. The products were characterized by their ${ }^{1} \mathrm{H}$ NMR or IR spectra and comparison with authentic samples (melting points). All yields referred to isolated pure products. The purity of products was determined by TLC and ${ }^{1} \mathrm{H}$ NMR. Also, reactions were monitored by TLCs utilizing plates cut from silica gel $60 \mathrm{~F}_{254}$ aluminum sheets.

A typical procedure for the oximation of aldehydes with $\mathrm{NH}_{2} \mathrm{OH} \cdot \mathrm{HCl} / \mathrm{H}_{2} \mathrm{O} / \mathrm{Microwave}$ irradiation system

In a round-bottomed flask $(10 \mathrm{~mL})$ a mixture of benzaldehyde $(0.106 \mathrm{~g}, \mathrm{I} \mathrm{mmol})$ in water $(5 \mathrm{~mL})$ was prepared. $\mathrm{NH}_{2} \mathrm{OH} \cdot \mathrm{HCl}(0.07 \mathrm{~g}, 1 \mathrm{mmol})$ was added. After fitting the flask to the external condenser at the inside of the oven the mixture was irradiated with a microwave oven $(30 \%$ power amplitude $\approx 300 \mathrm{~W}$ ) for $90 \mathrm{sec}$. The progress of the reaction was monitored by TLC (eluent: $\mathrm{CCl}_{4} / \mathrm{Et}_{2} \mathrm{O}: 5 /$ 2). After completion of the reaction, the precipitate Z-benzalde oxime $(0.115 \mathrm{~g}, 95 \%$ yield, table 1 , entry 1) was filtered and washed with water and air-dried without further purification.

\section{A typical procedure for the oximation of ketones} with $\mathrm{NH}_{2} \mathrm{OH} \cdot \mathrm{HCl} / \mathrm{H}_{2} \mathrm{O} / \mathrm{Microwave}$ irradiation system

In a round-bottomed flask (10 $\mathrm{mL})$ a solution of acetophenone $(0.120 \mathrm{~g}, \mathrm{I} \mathrm{mmol})$ in waterethanol $(96 \%)(5: 1 \mathrm{~mL})$ was prepared. $\mathrm{NH}_{2} \mathrm{OH} \cdot \mathrm{HCl}$ $(0.14 \mathrm{~g}, 2 \mathrm{mmol})$ and was added. After fitting the flask to the external condenser at the inside of the oven the mixture was irradiated with a microwave oven $(30 \%$ power amplitude $\approx 300 \mathrm{~W})$ for $130 \mathrm{sec}$. The progress of the reaction was monitored by TLC (eluent: $\mathrm{CCl}_{4} / \mathrm{Et}_{2} \mathrm{O}: 5 / 2$ ). After completion of the reaction the precipitate i.e.E-acetophenone oxime (0.126 g, 93\% yield, table 1 , entry 8$)$ was filtered and washed with water and air-dried without further purification.

\section{CONCLUSION}

In conclusion, the oximation of a variety of carbonyl compounds such as aldehydes, ketones 
was carried out efficiently with $\mathrm{NH}_{2} \mathrm{OH} \cdot \mathrm{HCl} / \mathrm{H}_{2} \mathrm{O}$ / Microwave irradiation system. The reactions were performed in water and water-ethanol to give $Z$-aldoximation isomers of aldehydes and Eoximaton of ketones in a perfect selectively. The oximation of aldehydes over ketones has not been accomplished successfully by this system. Also, this oximation system has the easily worked up.
Therefore, this new protocol for the oximation of carbonyl compounds could be a useful addition to the present methodologies.

\section{ACKNOWLEDGEMENTS}

The authors gratefully appreciated the financial support of this work by the research council of Islamic Azad University branch of Mahabad.

\section{REFERENCES}

1. (a) Loupy, A. Microwaves in Organic Synthesis; JohnWiley \& Sons, New York 2002.

(b) Kidwai, M. Pure Appl. Chem., 2001; 73: 147.

2. (a) Nagendrappa, G. Resonance., 2002; 59.

(b) Varma, R. S.; Namboodiri, V. V. Pure Appl. Chem., 2001; 73: 1309.

(c) Varma, R. S. Green Chem., 1999; 43.

3. (a) Grieco, P. A. Organic Synthesis in Water; Blackie Academic \& Professional, New York, 1998.

(b) Adams, D. J.; Dyson, P. J.; Tavener, S. J. Chemistry in Alternative Reaction Media; John Wiley \& Sons, New York, 2003.

(c) Zeynizadeh, B.; Setamdideh, D. J. Chin. Chem. Soc., 2005; 52: 1179.

4. Setamdideh, D.; Khezri, B.; Esmaeilzadeh, S. J. Chin. Chem. Soc., 2012; 59: 1119.

5. Setamdideh, D.; Karimi, Z.; Rahimi, F. Orient. J. Chem., 2011; 27: 1621.

6. Setamdideh, D.; Khezri, B.; Mollapour, M. Orient. J. Chem., 2011; 27: 991.

7. Setamdideh, D.; Khezri, B.; Rahmatollahzadeh, M.;Aliporamjad, A. Asian J. Chem. 2012; 24: 3591.

8. Setamdideh, D.; Rafig, M. E-J. Chem., 2012; 9: 2345.

9. Setamdideh, D.; Rahmatollahzadeh, M. J. Mex. Chem. Soc., 2012; $56: 169$.

10. Setamdideh, D.; Ghahremani, S. S. Afr. J.
Chem., 2012; 65: 91.

11. Setamdideh, D.; Hasani, S.; Noori, S. J. Chin. Chem. Soc., 2013; 60: 1267.

12. Pourhanafi, S.; Setamdideh, D.; Khezri, B. Orient. J. Chem. 2013; 29: 709.

13. Setamdideh, D.; Khezri, B.; Rahmatollahzadeh, M. J. Serb. Chem. Soc., 2013; 79: 1 .

14. Mohamadi, M.; Setamdideh, D.; Khezri, B. Org. Chem. Inter., doi:10.1155/2013/127585 2013.

15. Latifi Mmaghani, E.; Setamdideh, D. Orient. J. Chem. 2013; 29: 953.

16. Kamari, R.; Setamdideh, D. Orient. J. Chem. 2013; 29: 497.

17. Setamdideh, D.; Khaledi, L. S. Afr. J. Chem., 2013; 66: 150.

18. Setamdideh, D.; Karimi, Z.; Alipouramjad, A. J. Chin. Chem. Soc., 2013; 60: 590.

19. Setamdideh, D.; Sepehraddin, F. J. Mex. Chem. Soc., 2014; 58: 22.

20. Azizi Asl, P.; Setamdideh, D. J. Chin. Chem. Soc., 2014; 61. doi:10.1002/jccs.201400049

21. Setamdideh, D.; Minaee, M. Orient. J. Chem. 2014; 30: 359.

22. Arefi, H.; Setamdideh, D. Orient. J. Chem. 2014; 30: 299.

23. Taie Hasanloie, S.; Setamdideh, D. Orient. J. Chem. 2014; 30: 341.

24. Xu, W; Wang, J.; Liu, C.; Chen, C. L. J. Chin. Chem. Soc. 2004; 51: 1259. 